\section{Contribuição de uma controvérsia sobre transgenia para a formação crítica de alunos do ensino médio}

\section{- Contribution of a Transgenic Controversy to the Critical Education of High School Students \\ - Contribución de una controversia sobre transgénica a la formación crítica de estudiantes de la escuela secundaria}

\section{Resumo}

Este artigo apresenta um estudo de caso cujo objetivo foi investigar o impacto de uma controvérsia no entendimento do tema transgenia em estudantes de ensino médio de um colégio público. A prática foi pensada com intenção de explorar cinco dimensões de um campo conhecido como Pensamento Crítico. $\bigcirc$ tema transgenia foi escolhido de forma estratégica, pois serviu de base para tratar de questões tecnocientíficas relativas ao campo CTs de ensino. A metodologia utilizada para coleta de dados contou com a aplicação de questionários (PIEARCTS e HCTA) pré e pós controvérsia, além do registro das falas dos participantes durante e após a prática. Foram aplicados os mesmos questionários em uma turma controle, porém, sem a realização da controvérsia. Os resultados mostraram não haver diferenças significativas entre os índices gerados pelo PIEARCTS, mas sim para certas dimensões do Pensamento medidas pelo HCTA. Neste caso, para identificar as diferenças, foram realizadas análises globais dos questionários, seguido de análises específicas por categorias e, finalmente, análises específicas pelo tipo de pergunta. Quanto ao registro das falas dos estudantes, consideramos que estas foram fundamentais para identificar criticidade na maneira de encarar uma temática tão polêmica quanto à dos transgênicos, favorecendo reflexões complementares a respeito da metodologia aplicada.

Palabras clave

CTS; piearcts; cytpencri; pensamiento crítico; transgenia.

\section{Marcello Miranda Ferreira Spolidoro* Alvaro Chrispino**}

Mestre em Ciência, Tecnologia e Educacão/ CEFET-RJ, Professor de Biologia do Colégio Pedro II, Rio de Janeiro, Brasil

Correo: mspolidoro@gmail.com

Orcid: 0000-000 1-6406-5071

* * Doutor em Educação/UFRJ, Professor do Programa de Pós-graduação em Ciência, Tecnologia e Educacão do Centro Federal de Educacão Tecnológica do Rio de Janeiro, Brasil Correo: alvaro.chrispino@gmail.com Orcid: 0000-000 1-9914-3471

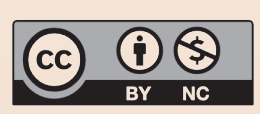

Segundo semestre de 2020 / ISSN 2665-3184 


\begin{abstract}
This article presents a case study whose objective was to investigate the impact of a controversy in the understanding of the transgenic theme in high school students from a public school. The practice was designed with the intention of exploring five dimensions of a field known as Critical Thinking. The transgenic theme was chosen in a strategic way, as it served as a basis for dealing with technoscientific issues related to the sTs field of teaching. The methodology used for data collection included the application of questionnaires (PIEARCTS and HCTA) pre and post controversy, in addition to recording the statements of the participants during and after the practice. The same questionnaires were applied in a control group, however, without carrying out the controversy. The results showed that there are no significant differences between the indices generated by PIEARCTS, but rather for certain dimensions of Thought measured by HCTA. In this case, to identify the differences, global analyzes of the questionnaires were carried out, followed by specific analyzes by categories and, finally, specific analyzes by the type of question. As for the record of the students' speeches, we consider that they were fundamental to identify criticality in the way of facing an issue as controversial as that of transgenics, favoring complementary reflections on the applied methodology.
\end{abstract}

Keywords

STS; piearcts; cytpencri; critical thinking; transgenic.

\title{
Resumen
}

El trabajo presenta un reporte de caso con el objetivo de investigar el impacto de una controversia sobre el tema transgenesis en estudiantes de escuelas públicas. La práctica fue diseñada con la intención de explorar cinco dimensiones de un campo conocido como Pensamiento Crítico. El tema transgenesis fue elegido estratégicamente, ya que sirvió como base para tratar los problemas tecnocientíficos relacionados con el campo de enseñanza de CTS. La metodología utilizada para la recopilación de datos incluyó la aplicación de cuestionarios (PIEARCTS y HCTA) antes y después de la controversia, además de registrar las declaraciones de los participantes durante y después de la práctica. Se aplicaron los mismos cuestionarios a un grupo de control, pero sin la controversia. Los resultados mostraron que no hay diferencias significativas entre los índices generados por PIEARCTS, pero sí para ciertas dimensiones del Pensamiento medido por HCTA. En este caso, para identificar las diferencias, se realizaron análisis globales de los cuestionarios, seguidos de análisis específicos por categorías y, finalmente, análisis específicos por tipo de pregunta. En cuanto al registro de los discursos de los estudiantes, consideramos que fueron fundamentales para identificar la criticidad en la forma de enfrentar un tema tan controvertido como el de los transgénicos, favoreciendo reflexiones complementarias sobre la metodología aplicada.

Palavras-chave

CTS; piearcts; cyłpencri; pensamento crítico; transgénesis. 


\section{Introdução}

A criação de novas maneiras de ministrar os conteúdos exigidos nos currículos escolares tem sido objetivo de muitos estudos na área de educação. Nestes trabalhos, o esforço é o de fornecer uma visão mais crítica do ensino e apresentar estruturas de caráter mais participativo, inclusivo, histórico, interdisciplinar e contextual. Assim, demonstra-se que o conhecimento científico é fruto de um contexto sociocultural e, portanto, não existe uma ciência neutra, pronta e acabada. Neste sentido, é interessante investigar diferentes metodologias para que possamos, em algum grau, provocar reflexões nos estudantes a respeito de temas tecnológicos na sociedade e colaborar com sua alfabetização científica e tecnológica.

Uma metodologia proposta para esta finalidade é a técnica da controvérsia, caracterizada por uma abordagem de ensino e intervenções didáticas que oferecem oportunidade de tratar de um tema polêmico sob diversos aspectos. Em nosso estudo, o tema trabalhado foi a transgenia, prática biotecnológica que envolve a transferência de uma sequência de material genético de um indivíduo para outro, em que este último passa a expressar a característica desejada sendo denominado "organismo geneticamente modificado" (OGM). É um tema polêmico e atrativo em educação por conta dos questionamentos levantados pelos estudantes nas aulas de Biologia/Ciências a respeito do conceito, aplicação e vantagem dessa prática.

trabalho proposto se inicia, então, com a avaliação das concepções e crenças dos alunos envolvidos a respeito das relações Ciência, Tecnología e Sociedade CTs. Para este fim, apresenta-se o Projeto Ibero-americano de Avaliação de Atitudes Relacionadas com Ciência, Tecnologia e Sociedade (PIEARCTS), um estudo de investigação colaborativa internacional.

Outro elemento utilizado para conhecer os possíveis impactos da controvérsia é o Pensamento Crítico, que consiste em um conjunto teórico que relaciona o pensar de forma crítica com processos racionais, reflexivos e avaliativos. A fim de mensurar o pensamento crítico dos estu- dantes, existem testes específicos que abordam de formas diferentes as dimensões desse campo da educação. $\bigcirc$ teste avaliativo aplicado foi - Questionário de Pensamento Crítico Halpern (Halpern Critical Thinking Assessment, OU HCTA), desenvolvido por Diane F. Halpern.

Este estudo pretendeu investigar qual o impacto de uma controvérsia para o entendimento do tema transgenia nos estudantes envolvidos na prática. Com isso, a pesquisa permitiu identificar as crenças e concepções dos alunos de ensino médio a respeito da transgenia utilizando a controvérsia, pautada em dimensões do pensamento crítico e em questões do PIEARCTS. Finalmente, pôde-se também verificar a capacidade de pensamento crítico dos alunos através da aplicação de questionários HCTA.

\section{A abordagem CTS}

As concepções clássicas da ciência e da tecnologia estão presentes em diversos setores do mundo acadêmico e nos meios de divulgação como essencialista e triunfalista. López-Cerezo (1998) explica, seguindo Maxwell (1984) e Echeverría (1995), que a ciência e a tecnologia, do ponto de vista clássico e herdado, só contribuiriam efetivamente para o bem-estar social se não houvesse interferência da sociedade, podendo funcionar, assim, com sua máxima eficácia. Seguindo esse raciocínio, diz ele que tanto uma quanto a outra eram apresentadas como entidades autônomas, concentradas nas mãos dos especialistas, principalmente no período da Segunda Guerra Mundial, quando havia um clima de grande otimismo acerca dessas questões e um apoio incondicional a elas. Dessa forma, ao longo dos anos, uma série de eventos - como a devastação causada por bombas e acidentes nucleares, o impacto de pesticidas sintéticos, entre outros - demonstrou que nem sempre há somente benefícios entre as relações tecnológicas e sociais. Isso trouxe à tona a dúvida sobre o uso de uma tecnologia a qualquer custo, o que colaborou com modificações no entendimento sobre as relações CTS, no sen-

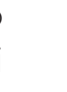


tindo de favorecer o surgimento de grupos de ativistas, que procuravam alertar os cidadãos a respeito dos riscos envolvidos no uso tecnologias (Chrispino, 2017). Considerando essa situação, Cutcliffe (2003) nos apresenta a concepção de CTS como um campo de estudo ativista, interdisciplinar e orientado a problemas que tratam de entender e responder complexidades da ciência moderna e da tecnologia na sociedade contemporânea.

Auler (2002) faz uma síntese desse panorama mítico, reescrevendo-os em três mitos principais: o da superioridade do modelo de decisões tecnocráticas; o da perspectiva salvacionista da Ciência e Tecnologia e do determinismo tecnológico.

E é na lógica contrária à dos mitos que defendemos a chamada "abordagem CTS", um caminho para a construção de propostas educacionais que levem a uma percepção diferenciada das situações envolvidas com C\&T. Espera-se, assim, que professores criem em suas aulas caminhos para a uma maior reflexão sobre pontos envolvendo as atividades científico-tecnológicas e sociais, colaborando, dessa maneira, com a alfabetização científica de seus alunos. Entretanto, para que isso ocorra, é importante haver mecanismos de identificação das crenças e posturas dos estudantes a respeito das relações CTS, a fim de que os novos caminhos educacionais considerem estas crenças e atitudes efetivas, o que é possível a partir da utilização do questionário do PIEARCTS.

\section{O Questionário PIEARCTS}

$\bigcirc$ PIEARCTS $^{1}$ é um projeto de avaliação cooperativa internacional em torno de temas de Natureza da Ciência e da Tecnologia (NCeT) ou Ciência, Tecnologia e Sociedade (CTS) que envolve pesquisadores de diferentes (Argentina, Brasil, Colômbia, Espanha, México, Panamá e Portugal, além dos pesquisadores associados). No Brasil, foi aplicado e difundido com recursos de Editais Universais do cNPq de 2007, 2011 e 2013 e resultou em dezenas de dissertações, teses e trabalhos nos programas de pós graduação do CEFET/RJ e da Universidade Cruzeiro do Sul (SP). Os desdobramentos destas pesquisas estão descritos, dentre outros, em Chrispino et al. (2017).

Acevedo et al. (2001) escrevem que a verificação de atitudes pode representar um importante obstáculo curricular no momento em que se abordam as inovações metodológicas que supõem a educação CTS, pois poucos professores estão dispostos a incorporar temas novos em suas aulas sem terem uma ideia clara de como avaliá-los.

questionário do PIEARCTS, portanto, tem como intenção verificar atitudes, valores e crenças dos estudantes e professores em questões ligadas à natureza da ciência e da tecnologia. Os resultados que surgem dessa metodologia visam estimular a elaboração de propostas educacionais envolvendo CTS que possam de alguma maneira contribuir com as modificações na prática docente e no conteúdo curricular vigente.

A estrutura do PIEARCTs engloba questões que apresentam o modelo de respostas e análises múltiplas e possuem a mesma estrutura: um texto inicial que apresenta

Ministério de Educação y Ciência (Projeto de pesquisa SEJ2007-67090/EDUC financiado pela Convocatória de ajudas a projetos de I+D 2007). 
uma situação-problema e, em seguida, uma lista de frases que representam diferentes alternativas de possíveis respostas a tal questão, ordenadas e identificadas sucessivamente com uma letra ( $A, B, C, D$, etc.). Posteriormente, o candidato deve atribuir um valor relativo ao seu grau de concordância com cada uma das frases apresentadas na situação-problema, na escala de Likert de 1 a 9. Especificamente, 1 corresponde ao menor grau de "desacordo" e 9 é o maior grau de "acordo".

Para analisar as respostas das questões, 16 especialistas analisaram as alternativas do questionário, classificando as respostas como plausíveis (P), ingênuas (I) e adequadas (A) (Vázquez et al., 2008; Bennássar et al., 2010). Isso nos fornece uma ideia da maneira como pensa quem é avaliado em relação às questões propostas.

Na presente pesquisa, optamos também por trabalhar com outro tipo de questionário, útil para coletar impressões adicionais sobre a forma de pensar dos estudantes.

\section{Pensamento crítico e o questionário HCTA}

Segundo Tenreiro-Vieira e Vieira (2000), instituições educacionais em todo o mundo iniciaram pesquisas sobre pensamento crítico na área de ensino, criando centros de pesquisa e investigação para realização de projetos na área do pensamento crítico, constituindo um campo de estudo com seu conjunto teórico específico. Assim, o esforço conduzindo por diversos autores, na intenção de conceituar o ensino baseado no campo do pensamento crítico, gerou uma variedade de perspectivas sobre este tema, entre eles a de Halpern (1996). Segundo a autora, o pensamento crítico é aquele que se mostra intencional, racional e dirigido para uma meta, um objetivo, envolvendo também a avaliação dos resultados obtidos. A autora deixa claro, ainda, que pensamentos subjacentes a hábitos diários mecanizados não estão incluídos no pensamento crítico, pois envolvem pouca avaliação consciente.
Tenreiro-Vieira (2004) nos traz uma reflexão a respeito da aplicação do pensamento crítico que muito se assemelha às intenções do campo CTS. Diz a autora:

Afirma-se ainda a necessidade de promover as capacidades de pensamento dos alunos, no contexto da educação em ciência, pois vive-se num mundo onde, cada vez mais, os cidadãos são chamados a intervir e a tomar posição sobre questões públicas, nomeadamente, sobre as implicações sociais da ciência e da tecnologia. Efectivamente, todos os estudantes de ciências serão elementos integrantes de uma sociedade e, enquanto cidadãos tornam-se responsáveis pelos riscos e benefícios do conhecimento, dos produtos e dos sistemas científicos e tecnológicos. (Tenreiro-Vieira, 2004, p. 2).

$\bigcirc$ pensamento crítico, portanto, dialoga fortemente com o ensino CTS, possuindo objetivos comuns no tocante às mudanças de percepções do ser humano, que são tão essenciais na quebra das visões distorcidas tratadas anteriormente.

HCTA contém cenários que ilustram situações cotidianas usadas para avaliar as seguintes dimensões: raciocínio verbal; análise de argumentos; pensamento como teste de hipóteses; probabilidade e incerteza; e tomada de decisão e resolução de problema. Cada dimensão possui cinco cenários, totalizando 25. Utiliza um formato duplo de perguntas combinando perguntas abertas e fechadas. As perguntas abertas permitem que o respondente ofereça um argumento, uma explicação, uma solução ou mesmo uma opinião sobre um determinado assunto, enquanto nas perguntas fechadas o respondente elege a opção que melhor responda ou resolva o problema formulado.

A aplicação dos dois questionários produzirá fundamentalmente dados quantitativos com possibilidade de extensão para o campo qualitativo de análise. Para que pudéssemos obter 
mais informações dos estudantes sem o intermédio dos questionários, optou-se também por aplicar uma intervenção de caráter qualitativo na tentativa de compreender melhor como pensam os respondentes. A controvérsia controlada, neste caso, é uma excelente técnica e pode trazer informações úteis para essa finalidade.

\section{A controvérsia e o tema transgenia}

Johnson e Johnson (2004) escrevem que a origem teórica das controvérsias se encontra no desenvolvimento cognitivo, nas teorias do equilíbrio psicológico-social e nas teorias do conflito. Defendem que essas três perspectivas explicam o porquê de as controvérsias produzirem discussões, das quais surgem conflitos cognitivos que poderão ser resolvidos no debate promovido pelo educador. Lembram que o debate não visa à abdicação de posições necessariamente e sim à criação de oportunidades para apresentar ideias e estar atento a argumentações do outro que pensa de forma divergente.

Para Hess (2009), o debate de temas controversos sob diferentes perspectivas está diretamente ligado ao pilar fundamental da democracia. A atividade desenvolvida utilizou-se da controvérsia enquanto polêmica, no sentido restrito da palavra, para enfatizar as questões postas orientando-se por rotinas didáticas, o que oferece bons resultados junto aos alunos (Melo et al., 2019; Chrispino, 2017; Reis, 2013; Gordillo et al., 2006).

Reis e Marques (2016) desenvolveram 10 módulos de ensino contendo temas controversos úteis para aplicação em sala de aula. Um dos módulos é chamado "Transgênicos: alimentos do futuro?", temática biotecnológica altamente controversa e que desperta, no geral, a curiosidade dos alunos, especialmente, nas aulas de Biologia. Pela lei 1 1 . 105 de 2005, nomeada de Lei de Biossegurança, um OGM é "um organismo cujo material genético (DNA/RNA) tenha sido modificado por qualquer técnica de engenharia genética (Brasil, 2005)".

Percebe-se, assim, que há uma preocupação com os desdobramentos existentes em processos que envolvem os organismos transgênicos. As empresas que optam por trabalhar com a produção e o desenvolvimento de oGMs investem tempo e dinheiro em C\&T procurando garantir condições de exploração comercial de seus produtos. Por outro lado, estudos têm suscitado dúvidas quanto aos possíveis prejuízos que esses organismos podem causar ao meio ambiente à saúde humana (Pelaez e Sbicca, 2002).

Takahashi et al. (2008), perceberam que alunos e professores não sabiam se eram capazes de consumir alimentos sabendo que eram transgênicos, provavelmente por não terem uma opinião mais elaborada sobre este assunto, o que torna ainda mais justificável a dedicação em trabalhar um tema controverso com estratégias diferenciadas de ensino em sala de aula.

\section{Descrição da experiência}

A pesquisa ocorreu durante o ano letivo de 2017 em escola da rede pública da cidade do Rio de Janeiro, com duas turmas de $3^{a}$ série do ensino médio 117 anos), selecionadas de forma aleatória, sendo que uma turma serviu de grupo controle, contendo 28 alunos, e outra serviu como grupo experimental, com um 
total de 35 alunos. Este tipo de abordagem é inspirado em sequências didáticas existentes no projeto CYTPENCRI ${ }^{2}$. As sugestões de trabalho metodológico envolvem, para cada turma, um pré-teste inicial seguida de uma intervenção didática específica e um pós-teste ao final. No geral, a indicação temporal do CYTPENCRI é que se realize essa sequência em três meses, da seguinte maneira: a aplicação do pré-teste marca o início da atividade, ou seja, o tempo zero. Um mês e meio após essa aplicação, se sugere a realização de uma intervenção didática e, finalmente, após mais um mês e meio, completando os três meses, se indica a aplicação do pós-teste e a coleta das impressões do grupo.

$\bigcirc$ pré-teste e o pós-teste também contaram com a aplicação de cinco cenários escolhidos do HCTA. $\bigcirc$ critério de seleção dos cenários foi baseado a partir do que gostaríamos que os alunos refletissem a respeito da transgenia, isto é, que eles pudessem ter contato com situações nas quais trabalhassem a formulação de hipóteses, o raciocínio verbal, a análise de argumentos, a probabilidade e incerteza e a resolução de problemas. Estas cinco dimensões do pensamento crítico podem facilmente se enquadrar em qualquer situação do dia a dia, especialmente quando trabalhadas em práticas didáticas direcionadas para temas polêmicos, tais qual a transgenia. Na turma controle tivemos 18 alunos participando do pré-teste e do pós-teste e na turma experimental foram 21 alunos.

Já para a controvérsia, a dinâmica foi pensada para que se pudessem confrontar argumentos de diversos atores sociais envolvidos com a questão científica, tecnológica e social dos transgênicos. Para cumprir este objetivo, os alunos da turma experimental foram divididos em seis grupos que puderam escolher quais

\footnotetext{
Educación de las competencias científica, tecnológica y pensamiento crítico mediante la enseñanza de temas de naturaleza de ciencia y tecnología. Proyecto EDU$2015-64642-R$ (MINECO/FEDER) con financiación del Ministerio de Economía y Competitividad de España y el Fondo Europeo de Desarrollo Regional.
}

atores sociais representariam durante as discussões da controvérsia a partir das opções:

- empresa produtora de organismos transgênicos

- agricultores a favor do plantio de transgênicos

- agricultores contra o plantio de transgênicos

- cientistas/pesquisadores a favor do desenvolvimento de transgênicos

- cientistas/pesquisadores contra desenvolvimento de transgênicos

- comissão de biossegurança

Primeiramente, cada grupo expôs seus argumentos iniciais, apresentando a postura em relação aos transgênicos. Em seguida, ocorreu o momento dedicado aos contra-argumentos. Aqui, abriu-se espaço para que os argumentos de um grupo pudessem ser contestados pelos demais grupos que se sentiram, porventura, "atacados" de alguma forma (realização de uma réplica, portanto). Finalmente, em uma última etapa, os grupos ficaram livres para deixar de lado seus olhares pré-estabelecidos do trabalho e cada integrante pôde comentar a respeito do tema utilizando posições pessoais.

A coleta das falas dos alunos ocorreu de forma manual pelo professor, enquanto os grupos se apresentavam e fomentavam a discussão. Para tratar dos dados coletados pelo PIEARCTS, foram utilizadas as médias dos índices atitudinais (IA) gerados a partir das respostas dos alunos para cada frase das três questões aplicadas, conforme descrito anteriormente.

$\bigcirc$ processamento dos dados coletados nos questionários sobre pensamento crítico se baseou primeiro na correção manual das respostas dos alunos. Cada um dos cinco cenários utilizados para montar o questionário já continha uma matriz de gabarito para que o aplicador pudesse se guiar e corrigir de maneira a dar a pontuação adequada para aquela resposta categorizada como crítica por parte da autora do teste, Diana Halpern. 
Posteriormente, os dados dos dois questionários foram organizados e sofreram análises estatísticas por meio do software SPSS, na intenção de comparar os valores dos pré-testes e dos pós-testes de cada uma das turmas, considerando a Significância ou Valor-p ${ }^{3}$ e o Tamanho de Efeito ${ }^{4}$.

A comparação entre pré-testes e pós-testes do questionário HCTA da turma experimental e da turma controle foi realizada pelo teste não-paramétrico, conhecido como teste de postos com sinais de Wilcoxon, utilizado em situações em que existem dois conjuntos de escores a serem comparados, sendo esses escores provenientes dos mesmos participantes. Já para o PIEARCTS, a comparação ocorreu analisando as médias de cada frase existente em cada uma das três questões (40221, 40531 e 80131 ) aplicadas aos alunos.

\section{Comparando os resultados obtidos pelo PIEARCTS}

\section{Questão 40221}

Esta questão traz como tema a influência da c\&T na sociedade a respeito da importância do conhecimento tecnocientífico para a tomada de decisões sociais. Ter conhecimento sobre os alimentos transgênicos e do impacto social de sua aceitação ou recusa traz mais legitimidade em qualquer que seja a posição do indivíduo.

A Figura 1 exibe os IA da turma controle tanto no pré-teste como no pós-teste. A Tabela 1 mostra o tratamento estatístico comparando os escores das duas condições (pré e pós-teste de cada frase da questão 40221) de forma a calcular sua significância e o tamanho do efeito (TE). Segundo estes dois parâmetros, não ocorreram mudanças estatisticamente significativas, pois todos os valores de significância se apresentaram maiores que 0,05 ( $p>0,05)$ além do te estar entre pequeno e médio (Tabela 1).

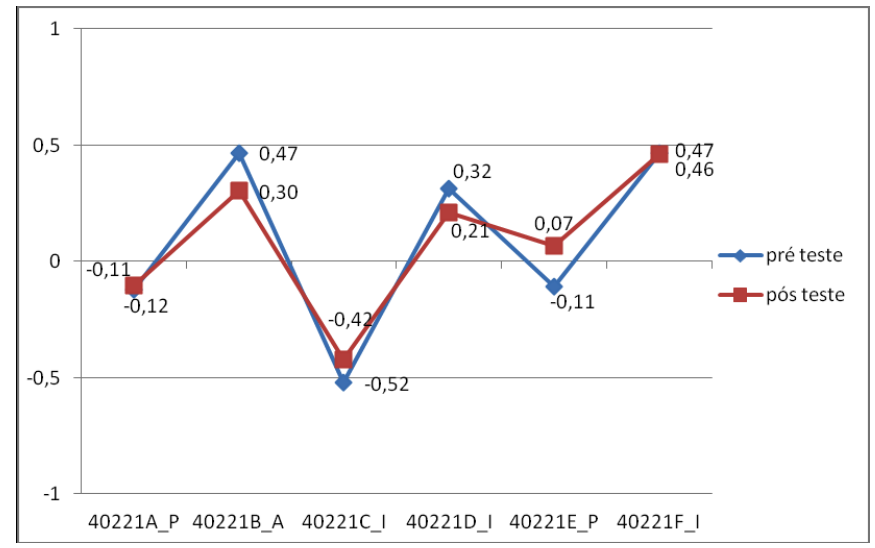

Figura 1. Índices atitudinais por frase da questão 40221 na turma controle

Fonte: Dados da pesquisa.

3 Cálculo da probabilidade de que os resultados obtidos ocorreram por acaso. Tradicionalmente, em estatística, se a significância alcançar um valor maior que 0,05, rejeita-se a hipótese experimental, assumindo a hipótese nula. Chamamos essa condição de resultado não significativo. Se o valor foi abaixo de 0,05, ocorre o contrário, isto é, assume-se a hipótese experimental e rejeita-se a hipótese nula. Chamamos, então, essa condição de resultado significativo.

4 Medida objetiva e padronizada da magnitude de um efeito observado. Tamanhos de efeitos na estatística são úteis porque eles fornecem uma medida direta da importância de um efeito em uma amostra. Baseado na escala de Cohen, um efeito pequeno é igual a 0,1 , um efeito médio é igual a 0,3 e um efeito grande é igual a 0,5. Esses valores ou o intervalo deles nos balizaram para que pudéssemos verificar se a controvérsia pôde de alguma forma contribuir com as previsões feitas na pesquisa. 
Tabela 1. Tratamento estatístico da questão 40221 na turma controle

\begin{tabular}{|c|c|c|}
\hline Frase & Significância & Tamanho de efeito \\
\hline 40221 A & 0,689 & $-0,065$ \\
\hline 40221 B & 0,088 & $-0,277$ \\
\hline 40221 C & 0,578 & $-0,09$ \\
\hline $40221 D$ & 0,485 & $-0,113$ \\
\hline 40221 E & 0,057 & $-0,309$ \\
\hline $40221 F$ & 0,551 & $-0,097$ \\
\hline
\end{tabular}

Fonte: Dados da pesquisa

A turma experimental apresentou um gráfico com nuances similares ao da turma controle, indicando que a diferença entre as atitudes e crenças dos dois grupos é pequena (Figura 2). Com relação à diferença entre os escores dos pré-testes e os pós-testes desta turma, os valores de significância não apontaram para diferenças significativas $(p>0,05)$ e os tamanhos de efeito se apresentaram como pequenos (Tabela 2).

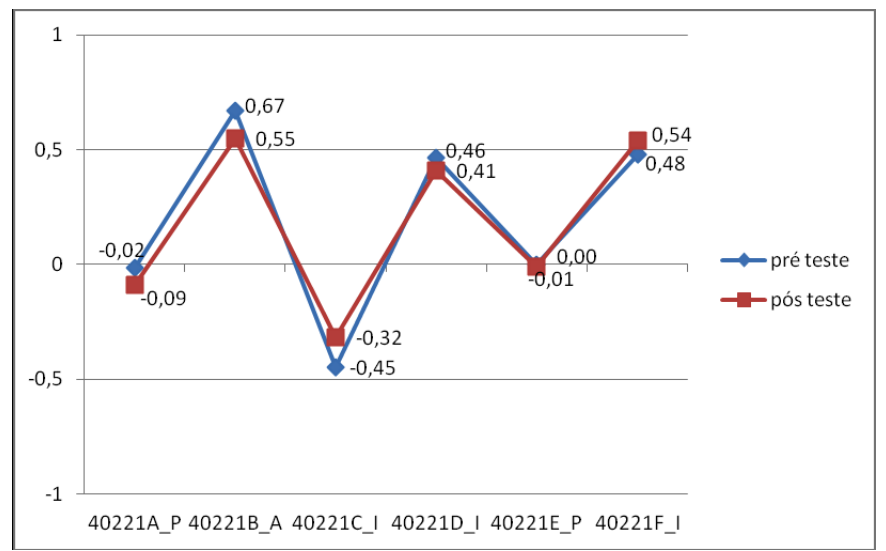

Figura 2. IA por frase da questão 40221 na turma experimental

Fonte: Dados da pesquisa.

Tabela 2. Tratamento estatístico da questão 40221 na turma experimental

\begin{tabular}{|c|c|c|}
\hline Frase & Significância & Tamanho de efeito \\
\hline 40221 A & 0,545 & $-0,078$ \\
\hline 40221 B & 0,262 & $-0,145$ \\
\hline 40221 C & 0,327 & $-0,127$ \\
\hline $40221 D$ & 1,00 & 0,00 \\
\hline $40221 E$ & 0,88 & $-0,019$ \\
\hline $40221 F$ & 0,583 & $-0,071$ \\
\hline
\end{tabular}

Fonte: Dados da pesquisa. 


\section{Questão 40531}

Esta questão traz como subtema o bem-estar econômico e aborda a ideia de que quanto mais tecnologia, melhor o nível de vida da sociedade. Toda frase que passa a ideia de que uma novidade tecnológica traz somente benefício deixando de lado suas desvantagens e efeitos colaterais é considerada ingênua pelos juízes. Já as frases que trazem consigo um teor crítico sobre o progresso tecnológico, são consideradas como adequadas.

Assim como na análise da questão anterior, os gráficos das duas turmas para a questão 40531 apresentaram curvas similares, indicando pouca diferença entre elas (Figuras 3 e 4). As diferenças entre os IA dos pré-testes e os pós-testes de cada uma das turmas também não se mostraram estatisticamente significativas $(p>0,05)$ e o tamanho de efeito se apresentou pouco expressivo, classificado como pequeno (Tabelas 3 e 4).

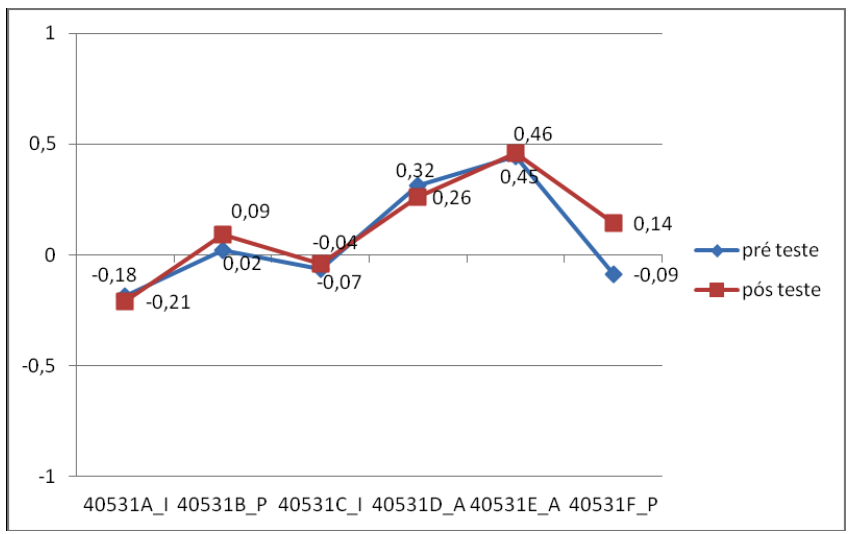

Figura 3. IA por frase da questão 40531 na turma controle

Fonte: Dados da pesquisa.

Tabela 3. Tratamento estatístico da questão 40531 na turma controle

\begin{tabular}{|c|c|c|}
\hline Frase & Significancia & Tamanho de efeito \\
\hline 40531A & 0,858 & $-0,029$ \\
\hline 40531B & 0,221 & $-0,199$ \\
\hline 40531C & 0,833 & $-0,034$ \\
\hline 40531D & 0,597 & $-0,086$ \\
\hline 40531E & 0,726 & $-0,057$ \\
\hline 40531F & 0,069 & $-0,295$ \\
\hline
\end{tabular}

Fonte: Dados da pesquisa. 


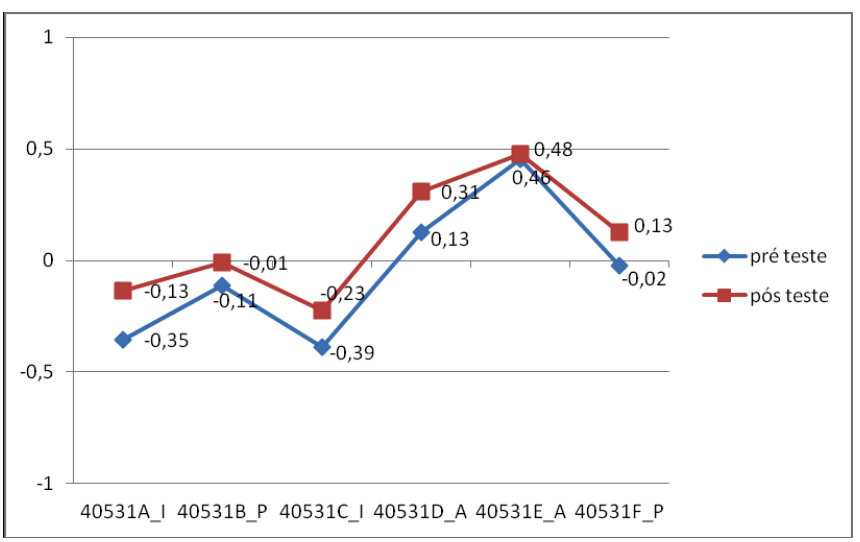

Figura 4. IA por frase da questão 40531 na turma experimental

Fonte: Dados da pesquisa.

Tabela 4. Tratamento estatístico da questão 40531 na turma experimental

\begin{tabular}{|c|c|c|}
\hline Frase & Significância & Tamanho de efeito \\
\hline 40531A & 0,082 & $-0,225$ \\
\hline 40531B & 0,074 & $-0,231$ \\
\hline 40531C & 0,089 & $-0,219$ \\
\hline 40531D & 0,180 & $-0,173$ \\
\hline 40531E & 0,810 & $-0,031$ \\
\hline 40531F & 0,046 & $-0,258$ \\
\hline
\end{tabular}

Fonte: Dados da pesquisa.

\section{Questão 80131}

Esta questão versa sobre decisões tecnológicas e aborda fatores que devem ser levados em consideração para que a sociedade usufrua de uma novidade tecnológica. É uma questão bem relacionada com a controvérsia a respeito dos transgênicos, pois muito se debateu sobre o fato de usar ou não os produtos transgênicos apontando vantagens e desvantagens.

Como nas questões analisadas anteriormente, as figuras também não apresentaram maiores diferenças entre os IA das duas turmas estudadas (Figuras 5 e 6) e os valores de significância e tamanho de efeito não se mostraram significativos, isto é, $p>0,05$ de baixo tamanho de efeito (Tabelas 5 e 6). 


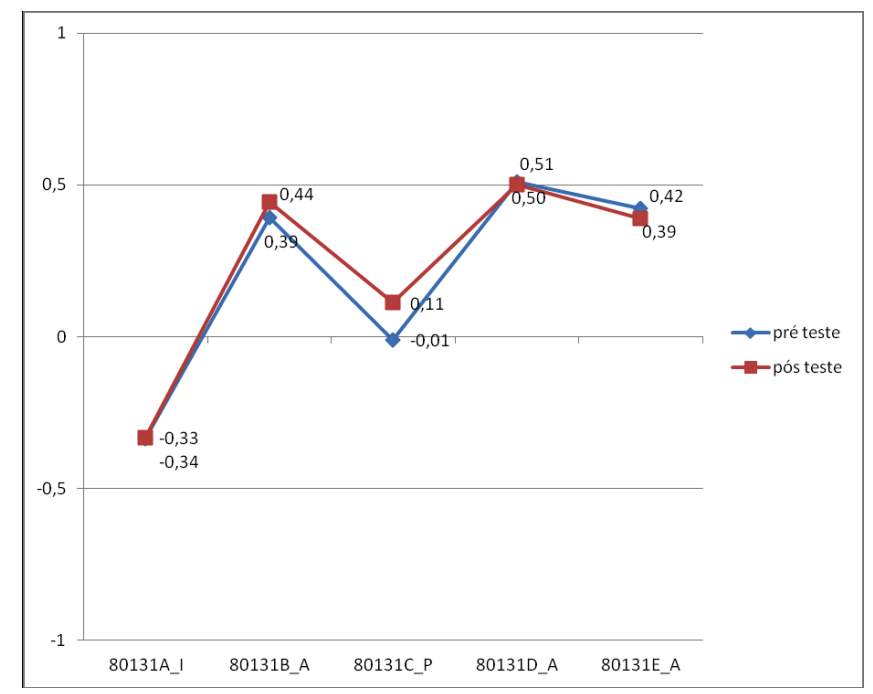

Figura 5. IA por frase da questão 80131 na turma controle

Fonte: Dados da pesquisa.

Tabela 5. Tratamento estatístico da questão 80131 na turma controle

\begin{tabular}{|c|c|c|}
\hline Frase & Significância & Tamanho de efeito \\
\hline $80131 \mathrm{~A}$ & 0,751 & $-0,51$ \\
\hline $80131 \mathrm{~B}$ & 0,499 & $-0,11$ \\
\hline $80131 \mathrm{C}$ & 0,167 & $-0,224$ \\
\hline $80131 \mathrm{D}$ & 1,000 & 0,000 \\
\hline $80131 \mathrm{E}$ & 0,85 & $-0,031$ \\
\hline
\end{tabular}

Fonte: Dados da pesquisa.

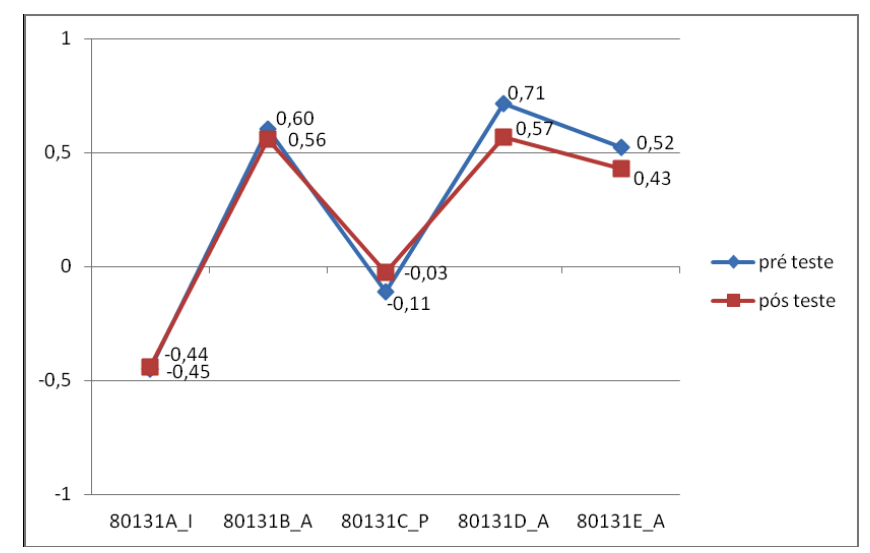

Figura 6. IA por frase da questão 80131 na turma experimental

Fonte: Dados da pesquisa. 
Tabela 6. Tratamento estatístico da questão 80131 na turma experimental

\begin{tabular}{|c|c|c|}
\hline Frase & Significância & Tamanho de efeito \\
\hline 80131 A & 0,931 & $-0,011$ \\
\hline $80131 B$ & 1,000 & 0,000 \\
\hline $80131 C$ & 0,332 & 0,125 \\
\hline $80131 D$ & 0,093 & $-0,216$ \\
\hline $80131 E$ & 0,508 & $-0,085$ \\
\hline
\end{tabular}

Fonte: Dados da pesquisa.

\section{Resultados obtidos do HCTA}

\section{Análise global dos questionários}

$\bigcirc$ tratamento estatístico utilizando o teste de Wilcoxon comparou inicialmente o valor total dos pré-testes com os dos pós-testes de todos os alunos da turma controle e da turma experimental. Primeiramente, na turma controle, 9 dos 18 alunos obtiveram um escore maior no pós-teste que no pré-teste contra 7 que, ao contrário, pontuaram mais no pré-teste. Apenas dois casos empataram suas pontuações no pré-teste e no pós-teste. Na turma experimental, 17 dos 21 alunos mostraram maior pontuação no pós-teste que no pré-teste, 2 obtiveram pontuação maior no pré-teste que no pós-teste e dois empataram seus escores. A tabela a seguir resume os resultados e fornece também O TE e a significância de cada realidade analisada.

Tabela 7. Tratamento estatístico dos questionários HCTA das turmas controle e experimental

\begin{tabular}{|c|c|c|c|c|c|c|}
\hline & $\begin{array}{c}\text { Total de } \\
\text { alunos }\end{array}$ & $\begin{array}{c}\text { Pós-teste } \\
\text { Pré-teste }\end{array}$ & $\begin{array}{c}\text { Pós-teste } \\
= \\
\text { Pré-teste }\end{array}$ & $\begin{array}{c}\text { Pós-teste } \\
> \\
\text { Pré-teste }\end{array}$ & Significância & $\begin{array}{c}\text { Tamanho } \\
\text { de efeito }\end{array}$ \\
\hline $\begin{array}{c}\text { Turma } \\
\text { Controle }\end{array}$ & 18 & 7 & 2 & 9 & 0,298 & 0,17 \\
\hline $\begin{array}{c}\text { Turma } \\
\text { Experimental }\end{array}$ & 21 & 2 & 2 & 17 & 0,002 & 0,48 \\
\hline
\end{tabular}

Fonte: Dados da pesquisa.

As duas turmas apresentaram resultados diferentes com relação, principalmente, ao rendimento no pós-teste. $\bigcirc$ TE lignorando o sinal) para as diferenças dessa análise global dos questionários da turma controle está ligeiramente acima do valor que, pela escala proposta por Cohen, é tido como pequeno $(0,1)$ e, além disso, a significância (p) aponta para um valor de 0,29 (p>0,05), indicando que o efeito não é estatisticamente significativo. Em outras palavras, rejeitamos nossa hipótese experimental, o que dá validade à hipótese nula, em que o efeito encontrado possui fortes chances de ser devido ao acaso. Já o resultado da turma experimental indica um TE E de
0,48 , entre médio $(0,3)$ e grande $(0,5)$, estatisticamente significativo, com valor de 0,002 ( $p<0,05)$, em que, no escopo dessa análise global dos questionários, confirmamos nossa hipótese experimental. Isso indica, na verdade, que a probabilidade de o efeito produzido ser obra do acaso é pequena.

\section{Análise específica por categoria}

Além de verificar os resultados comparando as pontuações totais dos questionários HCTA, decidimos também analisar de forma mais específica as diferentes dimensões (categorias) do pensamento crítico. Quando calculamos as

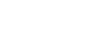


médias dos valores obtidos pelos alunos das diferentes turmas em cada uma das categorias (hipótese, raciocínio verbal, argumentação, etc.), identificamos uma diferença muito pequena entre os valores comparados entre os pré-testes e os pós-testes da turma controle, muito embora todos os valores dos pós-teste tenham sido ligeiramente maiores dos que os do pós-teste. Já na turma experimental, as diferenças estabelecidas foram maiores que os da turma controle, indicando também valores maiores no pós-teste deste grupo, o que suscita reflexões sobre a prática exercida pela controvérsia pode ter sido responsável pelo efeito gerado nas diferenças entre estas médias.

$\bigcirc$ tratamento estatístico comparou os valores totais obtidos pelos alunos do grupo controle e do grupo experimental em cada uma das cinco categorias do questionário e forneceu também a significância e o TE dessa diferença. As figuras a seguir exibem a distribuição dos índices (médias) nas duas turmas por dimensões do pensamento crítico e as tabelas mostram a significância e o TE.

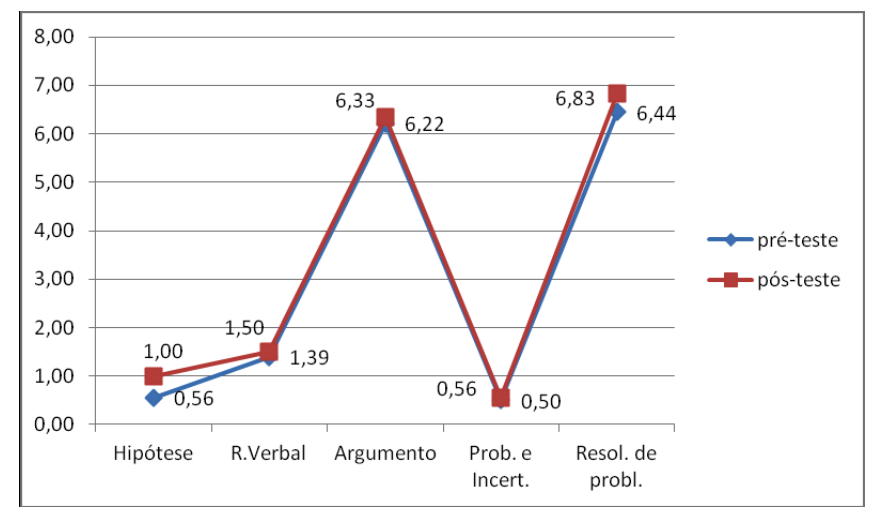

Figura 7. Valor dos índices pelas dimensões do pensamento crítico (turma controle)

Fonte: Dados da pesquisa.

Tabela 8. Tratamento estatístico das dimensões do pensamento crítico na turma controle

\begin{tabular}{|c|c|c|}
\hline Dimensão & Significância & Tamanho de efeito \\
\hline Hipótese & 0,07 & $-0,30$ \\
\hline Raciocínio verbal & 0,68 & $-0,07$ \\
\hline Argumento & 1,00 & 0,00 \\
\hline Probabilidade e incerteza & 0,71 & $-0,06$ \\
\hline Resolução de problemas & 0,27 & $-0,18$ \\
\hline
\end{tabular}

Fonte: Dados da pesquisa. 


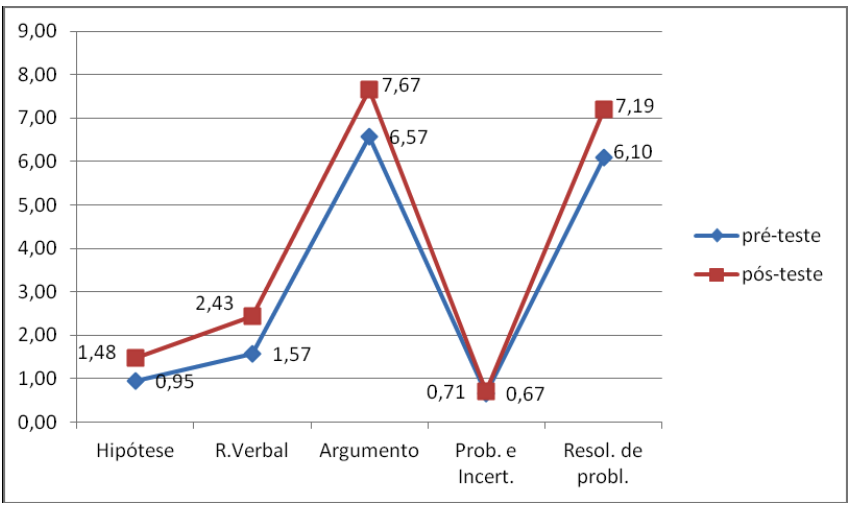

Figura 8. Valor dos índices pelas dimensões do pensamento crítico (turma experimental)

Fonte: Dados da pesquisa

Tabela 9. Tratamento estatístico das dimensões do pensamento crítico na turma experimental

\begin{tabular}{|c|c|c|}
\hline Dimensão & Significância & Tamanho de efeito \\
\hline Hipótese & 0,21 & $-0,19$ \\
\hline Raciocínio verbal & 0,01 & $-0,39$ \\
\hline Argumento & 0,04 & $-0,31$ \\
\hline Probabilidade e incerteza & 0,76 & $-0,05$ \\
\hline Resolução de problemas & 0,03 & $-0,34$ \\
\hline
\end{tabular}

Fonte: Dados da pesquisa.

Na turma controle, nota-se que apenas a categoria hipótese apresentou aparentemente uma diferença acentuada quando comparada com as demais. O TE dessa diferença alcançou 0,3 , o que denota um efeito médio nesse quesito. Já a análise das demais diferenças mostra um TE bem menor, transitando entre o mínimo de 0,00 (sem efeito) e 0,18 (ligeiramente acima do estabelecido para efeito pequeno). No caso da significância de todas as categorias dessa turma, seu valor indica rejeição da hipótese experimental ( $p>0,05)$, indicando que estas diferenças não são estatisticamente significativas.

Observamos, entretanto, na turma experimental, tamanhos de efeito entre médio $(0,3)$ e grande $(0,5)$ para três das cinco categorias. Além disso, a significância dessas três categorias apresentou relevância estatística com $p<0,05$, valor que valida nossa hipótese experimental. A categoria hipótese, juntamente com a de probabilidade e incerteza, foram as que apresentaram menor magnitude do efeito 10,19 e 0,05, respectivamente) e um valor de $p>0,05$, que rejeita a hipótese experimental, indicando um resultado não significativo especificamente nesses quesitos.

\section{Análise específica pelo tipo de pergunta}

Como as dimensões trabalhadas pelo questionário HCTA possuem questões abertas e fechadas, optamos também por esmiuçar ainda mais a análise, dando atenção a essas modalidades de perguntas. Nesse tipo de análise, a turma controle não apresentou nenhum diferencial que merecesse destaque (Tabela 10), pois os resultados referentes ao tamanho de efeito e da significância se mantiveram baixos e não significativos, respectivamente, em absolutamente todos os casos. 
Tabela 10. Análise específica por tipo de pergunta na turma controle

\begin{tabular}{|c|c|c|c|c|c|c|}
\hline Dimensões & $\begin{array}{l}\text { Tipo de } \\
\text { pergunta }\end{array}$ & $\begin{array}{c}\text { Pós-teste } \\
< \\
\text { Pré-teste }\end{array}$ & $\begin{array}{c}\text { Pós-teste } \\
\quad= \\
\text { Pré-teste }\end{array}$ & $\begin{array}{c}\text { Pós-teste } \\
> \\
\text { Pré-teste }\end{array}$ & Significância & $\begin{array}{l}\text { Tamanho } \\
\text { de efeito }\end{array}$ \\
\hline \multirow{2}{*}{ Hipótese } & Aberta & 0 & 15 & 3 & 0,083 & $-0,29$ \\
\hline & Fechada & 1 & 13 & 4 & 0,129 & $-0,25$ \\
\hline \multirow{2}{*}{$\begin{array}{c}\text { Raciocínio } \\
\text { verbal }\end{array}$} & Aberta & 3 & 11 & 4 & 0,931 & $-0,01$ \\
\hline & Fechada & 3 & 11 & 4 & 0,527 & $-0,11$ \\
\hline \multirow{2}{*}{$\begin{array}{l}\text { Análise de } \\
\text { argumentos }\end{array}$} & Aberta & 5 & 10 & 3 & 0,763 & $-0,05$ \\
\hline & Fechada & 4 & 8 & 6 & 0,372 & $-0,15$ \\
\hline \multirow{2}{*}{$\begin{array}{c}\text { Probabilidade } \\
\text { e incerteza }\end{array}$} & Aberta & 3 & 12 & 3 & 1,000 & 0,00 \\
\hline & Fechada & 2 & 13 & 3 & 0,655 & $-0,07$ \\
\hline \multirow{2}{*}{$\begin{array}{c}\text { Resolução de } \\
\text { problemas }\end{array}$} & Aberta & 6 & 10 & 2 & 0,157 & $-0,24$ \\
\hline & Fechada & 3 & 4 & 11 & 0,110 & $-0,27$ \\
\hline
\end{tabular}

Fonte: Dados da pesquisa.

Na turma experimental observamos que as questões abertas de raciocínio verbal e as questões fechadas da categoria "resolução de problemas" se ressaltaram apresentando um valor de efeito entre médio $(0,3)$ e grande $(0,5)$, com significância no nível $p<0,05$, contrariando a hipótese nula e sugerindo que a controvérsia possa ter tido algum efeito nesses quesitos específicos (Tabela 11 ). Já os outros tipos de perguntas não apresentaram significância nem tamanho de efeito com grande relevância estatística.

Tabela 11 . Análise específica por tipo de pergunta na turma experimental

\begin{tabular}{|c|c|c|c|c|c|c|}
\hline Dimensões & $\begin{array}{l}\text { Tipo de } \\
\text { pergunta }\end{array}$ & $\begin{array}{c}\text { Pós-teste } \\
< \\
\text { Pré-teste }\end{array}$ & $\begin{array}{c}\text { Pós-teste } \\
= \\
\text { Pré-teste }\end{array}$ & $\begin{array}{c}\text { Pós-teste } \\
> \\
\text { Pré-teste }\end{array}$ & Significância & $\begin{array}{l}\text { Tamanho } \\
\text { de efeito }\end{array}$ \\
\hline \multirow{2}{*}{ Hipótese } & Aberta & 3 & 10 & 8 & 0,088 & $-0,26$ \\
\hline & Fechada & 5 & 8 & 8 & 0,470 & $-0,11$ \\
\hline \multirow{2}{*}{$\begin{array}{c}\text { Raciocínio } \\
\text { verbal }\end{array}$} & Aberta & 0 & 11 & 10 & 0,004 & $-0,45$ \\
\hline & Fechada & 3 & 14 & 4 & 0,705 & $-0,06$ \\
\hline \multirow{2}{*}{$\begin{array}{l}\text { Análise de } \\
\text { argumentos }\end{array}$} & Aberta & 1 & 15 & 5 & 0,084 & $-0,27$ \\
\hline & Fechada & 4 & 8 & 9 & 0,114 & $-0,24$ \\
\hline \multirow{2}{*}{$\begin{array}{c}\text { Probabilidade } \\
e \\
\text { incerteza }\end{array}$} & Aberta & 4 & 12 & 5 & 0,755 & $-0,05$ \\
\hline & Fechada & 0 & 19 & 2 & 0,157 & $-0,22$ \\
\hline \multirow{2}{*}{$\begin{array}{c}\text { Resolução de } \\
\text { problemas }\end{array}$} & Aberta & 6 & 10 & 5 & 0,468 & $-0,11$ \\
\hline & Fechada & 5 & 2 & 14 & 0,003 & $-0,46$ \\
\hline
\end{tabular}

Fonte: Dados da pesquisa. 


\section{Discussão pós-debate}

momento pós-debate, quando foi sugerido que eles não mais considerassem as opiniões do grupo de interesse assumido e sim o que eles entenderam sobre os transgênicos, trouxe algumas reflexões importantes:

Obviamente as empresas estão preocupadas com os lucros. Vai ser sempre assim. Enquanto tiver dando lucro, muitas coisas vão ser atropeladas. Vão continuar comercializando e provavelmente vão conseguir permissão para evitar colocar o "T" nas embalagens dos alimentos. $\bigcirc$ agronegócio tem muito dinheiro e compra votos no Senado... (estudante 19).

$\bigcirc$ que se pode perceber, em linhas gerais, é que os alunos, nos seus comentários, parecem enxergar que uma nova tecnologia pode trazer malefícios, além de ser interessante para um grupo e não interessante para outro. Ou seja, pelo menos na ocasião do debate e de suas exposiç̃oes, os estudantes demonstram contrariedade em algum grau aos conceitos míticos da ciência herdada. Essas questões ficam visíveis, por exemplo, no comentário que tratava da posição das empresas produtoras dos transgênicos que, segundo um aluno, tem sua visão prioritária no lucro e não no que acontece de ruim para a sociedade (estudante 19).

Eu acredito que os transgênicos trazem mais malefícios do que benefícios, professor. Gosto da ideia de aumentar a produtividade das plantações, comprovada por alguns trabalhos, mas acontece que acho ruim que pequenos agricultores percam seu espaço pro agronegócio. Essa situação é muito ruim socialmente falando e piora as desigualdades. (estudante 2).

Eu comeria transgênicos tranquilamente porque, pelo que vi, não há comprovação científica mesmo de que eles façam mal. Tudo bem que os ratos apresenta- ram tumores depois de um tempo, mas como foi dito, não há nenhum trabalho que mostre um ser humano morrendo por causa dos transgênicos. (estudante 13).

No entanto, a questão da chamada comprovação científica também foi muito discutida pelos alunos, pois muitos dos comentários envolvem esse jargão bastante comum no marketing aplicado a alimentos novos nos mercados. Por exemplo, estudantes relataram que consumiriam transgênicos porque até hoje não houve nada "comprovado cientificamente" relacionado com os possíveis males que esses produtos possam causar à saúde humana (estudante 13). Outra questão na opinião dos alunos e que envolve validação pela ciência é a produtividade aumentada das culturas, que passa a ser um ponto a favor dos transgênicos, embora haja outros problemas envolvidos (estudante 2). Assim, nota-se um apanhado de posições consonantes com a visão clássica e herdada de ciência (os mitos) e posturas que vão contra a essas visões, quando incluem questões sociais e humanísticas nos temas tratados.

Não consumiria porque não gostaria de ter que sofrer mais tarde com alguma doença que pode aparecer. Entendo as pessoas que comem, mas talvez elas nem tenham conhecimento da polêmica que é. Vi nos documentários e já vi na tevê que muitas pessoas não têm a mínima noção do que significa alimento geneticamente modificado. Saber do que se trata faz muita diferença. (estudante 8).

.... porque falar sobre assuntos polêmicos é muito complicado. Exige discussão, leitura e documentários sobre um tema para formar uma opinião forte... (estudante 11 ).

Percebe-se também o fato de que os alunos expressam opiniões baseadas em ideias sensacionalistas tratadas pela mídia, pois relatam que se informam sobre um tema assistindo a documentários e a programas de tevê, que obviamente trazem informações direcionadas a seus próprios interesses e opiniões, 
além de exageros ou visões distorcidas sobre a temática (estudantes 8 e 1 1). A controvérsia cumpre um importante papel para que um tema seja apresentado e trabalhado em diversas óticas, evitando a posição passiva dos estudantes. Carneiro (20 14) enfatiza que as posições dos estudantes em práticas de controvérsias se mostram mais consistentes e críticas, consequência direta da pesquisa e da discussão dos temas trabalhados por eles próprios.

Qual é a diferença de ser contra comer transgênicos se o milho modificado é usado pra fazer a ração pros bois? A gente dá ração feita de milho transgênico para o boi e depois come a carne dele.... pra mim dá no mesmo. (estudante 22).

Algumas falas também chamaram atenção por envolver explicitamente as dimensões do pensamento crítico. Alunos, por exemplo, que questionam a lógica de um processo de consumo como a ideia expressa de que não comemos milho transgênico, mas comemos o animal que é alimentado por esse milho (estudante 22), exercem a dimensão do raciocínio verbal e análise de argumentos. De fato, as perguntas abertas da modalidade raciocínio verbal na turma experimental (Tabela 11) apresentaram índices estatisticamente significativos e tamanho de efeito relevantes, indicando que os alunos podem demonstrar linhas de pensamento crítico se forem estimulados a questionar e a debater um determinado tema. Outros alunos já levantam dúvidas sobre a ideia de os transgênicos trazerem mais vantagens que as modalidades de alimentos da mesma espécie cruzadas entre si, exercendo, dessa maneira, as dimensões de hipótese e de probabilidade e incerteza.

Finalizando as reflexões, notamos que, dependendo da métrica utilizada, podemos ou não verificar mudanças na postura dos alunos quanto a assuntos trabalhados antes e depois de uma intervenção didática. Vidal (2016) considera que não haver variações em alguns resultados não significa necessariamente falha nos objetivos de um trabalho e que é possível ampliar os estudos utilizando metodologias e investigações diferenciadas. Deve-se, portanto, estar atento aos dados qualitativos de uma prática como esta, para que se possa problematizar e analisar as percepções por mais de uma via.

\section{Considerações finais}

A prática da controvérsia promoveu na turma uma reflexão mais aprofundada a respeito de um tema que contém diversas questões sociais embutidas, mas que, quando é tratado somente de forma expositiva e tradicional, não sensibiliza os alunos como ocorreu. Mesmo com as limitações da pesquisa, encontramos indícios de dimensões do pensamento crítico sendo trabalhados pelos alunos ao longo do tempo do estudo, seja no ato da realização da controvérsia, seja nos resultados dos questionários HCTA, especialmente quando analisadas as diferentes categorias. $\bigcirc$ PIEARCTS não demonstrou variações significativas quanto a crenças e atitudes, havendo somente ganhos pontuais, o que sugere que esta métrica talvez não aponte eventuais mudanças. Porém, mesmo que o resultado estatístico não tenha identificado diferenças relevantes no PIEARCTS, os comentários coletados ao final da controvérsia demonstraram uma mudança mais acentuada frente às crenças e atitudes em CTS. 
Nosso estudo possui restrições que são resultados do pouco tempo disponível para as atividades e para as avaliações posteriores. Fica a dúvida de se a organização de uma controvérsia envolvendo mais encontros ou mesmo mais tempo de preparação prévia com os alunos é capaz de trazer maiores contribuições, especialmente no desenvolvimento de habilidades do pensamento crítico e nas modificações das crenças e atitudes relacionadas à ciência e tecnologia.

É válido mencionar, ainda, que a controvérsia contribuiu estimulando o interesse e provocando impactos positivos em parte dos alunos de ambas as turmas. Por isso, consideramos importante ter sempre em mente que, se almejamos modificar o cenário do ensino atual e aos poucos formar indivíduos com maior criticidade e participação, devemos, então, nos esforçar para entender as formas de abordagem mais atrativas aos estudantes e aplicá-las de modo planejado e adaptado a cada sala de aula.

\section{Referências}

Acevedo, J., Acevedo, P., Manassero, M. e Vázquez, A. (2001). Avances metodológicos en la investigación sobre evaluación de actitudes y creencias CTS. Revista Iberoamericana de Educación, (1), 1-14.

Auler, D. (2002). Interações entre ciências-tecnologia-sociedade no contexto da formação de professores de ciências (Tese de doutorado). Universidade Federal de Santa Catarina, Brasil.

Bennássar, A., Vázquez, Á., Manassero, M. e García-Carmona, A. (Coord.). (2010). Ciencia, tecnología y sociedad en Iberoamérica. OEI.

Brasil. (2005). Lei $N^{0} 11$. 105, de 24 de março de 2005. Portal do Planalto.

Carneiro, M. (2014). Técnica de controvérsia aplicada ao tabagismo (Dissertação de mestrado). Centro Federal de Educação Tecnológica Celso Suckow da Fonseca (CEFET), Rio de Janeiro, Brasil.
Chrispino, A. (2017). Introdução aos enfoques CTS-Ciência, Tecnologia e Sociedade-na educação e no ensino. OEl.

Chrispino, A, Silva, M., Melo, T. e Albuquerque, M. (2017). Do resultado da pesquisa às ações de intervenção na prática escolar: a contribuição de um grupo de pesquisa CTS. Da Investigação às Práticas, 7(2), 91-115.

Cuticliffe, S. (2003) Ideas, Máquinas y valores. Los Estudios de Ciencia, Tecnología y Sociedad. Anthropos; UNAM.

Echeverría, J. (1995). Filosofía de la ciencia. Akal.

Gordillo, M., Ramírez, R., Álvarez, A., García, E., Gallbart, J., Portilla, C. e Marcos, M. (2006). Controversias tecnocientíficas. Diez casos simulados sobre ciencia, tecnología, sociedad y valores. Colección Educación en valores. OEI.

Halpern, D. (1996). Thought and knowledge: An introduction to critical thinking (3rd Ed). Lawrence Erlbaum Associates.

Hess, D. (2009). Controversy in the classroom: The democratic power of discussion. Ed. Routledge.

Johnson, D. e Johnson, R. (2004). Como reducir la violencia en las escuelas. Paidós.

López-Cerezo, J. (1998). Ciencia, tecnología y sociedad: el estado de la cuestión en Europa y Estados Unidos. Revista Iberoamericana de Educación, (18), 41-68.

Maxwell, N. (1984). From knowledge to wisdom: A revolution in the aims \& methods of science. Basil Blackwell.

Melo, T., Albuquerque, M. e Chrispino, A. (2019). Controvérsias e CTs: analisando os textos da produção científica em Ensino CTS no Brasil. Indagatio Didactica, (1 1), p. 253-265.

Pelaez, V. e Sbicca, A. (2002). Organismos geneticamente modificados: a face não revelada pela ciência. UFPR. 
Reis, P. (2013). Da discussão à ação sócio-política sobre controversias sócio-científicas: uma questão de cidadania. Ensino de Ciências e Tecnologia em Revista, 3(1), 1-10.

Reis, P. e Marques, A. (2016) A investigação e inovação responsáveis em sala de aula. Módulos de ensino IRRESISTIBLE. Universidade de Lisboa. Instituto de Educação.

Takahashi, J., Martins, P. e Quadros, A. (2008) Questões tecnológicas permeando o ensino de química: o caso dos transgênicos. Química Nova na Escola, (29), 3-7.

Tenreiro-Vieira, C. (2004). Produção e avaliação de atividades de aprendizagem de ciências para promover o pensamento crítico dos alunos. Revista Iberoamericana de Educación, (6), 1-17.

Tenreiro-vieira, C. e Vieira, R. (2000). Promover o pensamento crítico dos alunos: propostas concretas para sala de aula. Porto Editora.

Vázquez, Á., Manassero, M., Acevedo, J. e Acevedo, P. (2008). Consensos sobre a natureza da ciência: a ciência e a tecnologia na sociedade. Química nova na escola, (27), 34-50.

Vidal, C. (2016). O tema CTS da indústria da guerra usando a técnica da controvérsia controlada no ensino médio (Dissertação de mestrado). Centro Federal de Educação Tecnológica Celso Suckow da Fonseca (CEFET), Rio de Janeiro, Brasil.

\section{Para citar este artículo:}

Spolidoro, M., e Chrispino, A. (2020). Contribuição de uma controvérsia sobre transgenia para a formação crítica de alunos do ensino médio. Tecné, Episteme y Didaxis: TED, (48), 203-222. https://doi.org/10.17227/ted.num48-12388 